\title{
ITCHING IN SYPHILIS *
}

WALTER J. HIGHMAN, M.D.

NEW YORK

Sabouraud has jestingly maintained that a series of two hundred dermatologic aphorisms would amply cover all known practical facts in the field. He included in his list the statement, "Itching lesions are nonsyphilitic," and he qualified this by the modification that of course some syphilitic lesions itched, but that in general they did not.

A search of the literature relevant to the theme of this paper was virtually fruitless. Except for the conventionally known facts that the small papular secondary syphiloderm, or syphilitic lichen and its derivatives, such as syphilitic acne, may itch, and particularly so in the negro, and that syphilids in general are slightly more likely to be pruriginous in blacks than in whites, I found only one reference (and this a most fragmentary one) to the subject in general. Phineas Abraham ${ }^{1}$ in discussing pruritus in syphilis states, "This is particularly apt to occur on the scalp, scrotum and perineum, and the front of the legs, as well as when the syphilid happens to be complicated with eczema or other pruritic skin affection. Very rarely, a pure syphilid may be intensely pruritic." The same author, in the same work, ${ }^{2}$ says of leukoplakia of the prepuce, that the resulting shrinking "is often accompanied by severe soreness and itching." In an effort to gather further data, I communicated with several syphilologists throughout the country, requesting pertinent references or reports of personal experiences. Only Dr. Herrman Goldenberg was able to recall a case, in the late Dr. Fred Leviseur's clinic at the Mount Sinai Dispensary, in which intense pruritus had accompanied multiple gummas of the forearm. Since pruritus is regarded as a symptom almost excluding the diagnosis of syphilis, I should like to report a case which illustrates the diagnostic danger of too unqualifiedly accepting this belief.

\section{REPORT OF CASES}

History.-I. M., married, a merchant, aged 49, consulted me on Aug. 12, 1920, for an itching scrotal eruption of a year's duration. The lesions gradually increased in number on the scrotum, and were also present sparsely elsewhere, one on the right wrist, one on the lower right abdominal quadrant. For

* Read at the Forty-Fourth Annual Session of the American Dermatological Association, Swampscott, Mass., June 2-4, 1921.

1. Abraham, Phineas, in Power and Murphy's System 5:10.

2. Idem. 5:153. 
a year the terminal phalanges of the right index finger had been red and swollen and painful, and the distal articulation was almost immobile.

The scrotal lesions itched intensely and almost continuously, both day and night. At times the finger pained. The man had had gonorrhea thirty years before, but denied syphilis, and a Wassermann test performed two months after the onset, or ten months prior to his first visit to me, had been negative. Aside from this, his clinical history contained nothing bearing on his skin lesions.

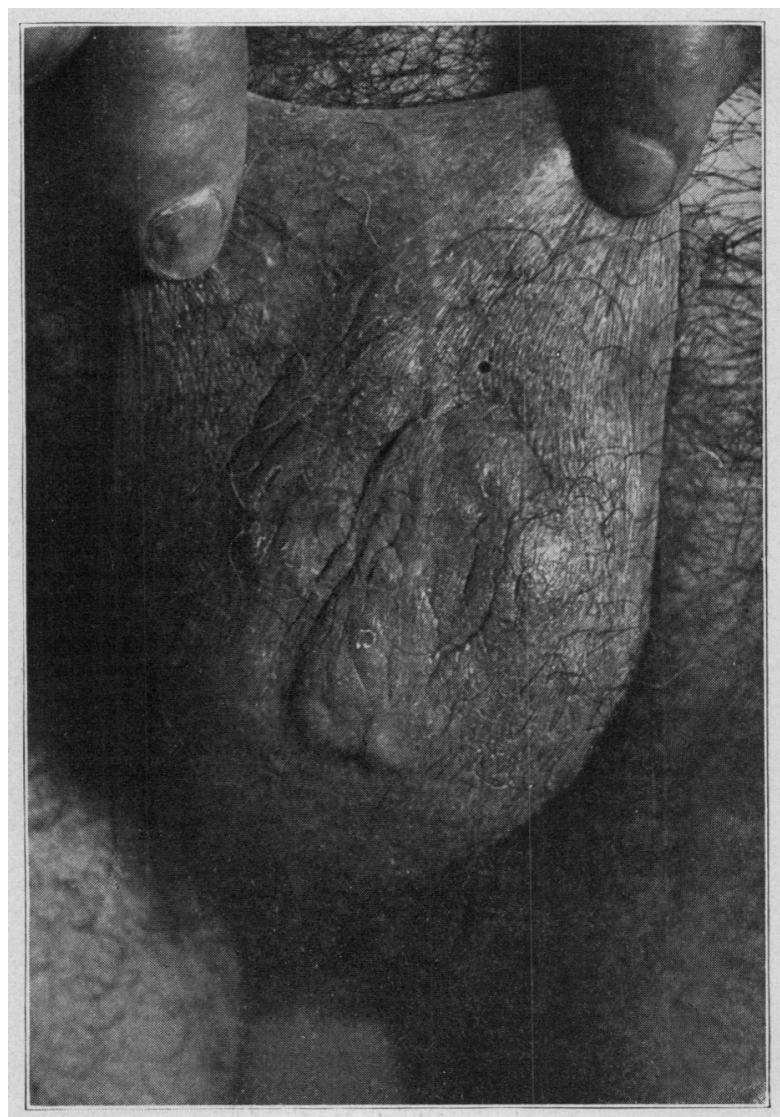

Scrotal eruption.

Examination.-The scrotum was studded with flat, annular violaceous or purple lesions, varying in diameter from 1 to $2 \mathrm{~cm}$. They were infiltrated, elastic and had a sharp margin, the rims of which were higher than the depressed or cup-shaped centers. Even where lesions were not visible, they could be felt as small disks inscrted in the cutis. A single, annular lesion existed on the right iower abdominal quadrant, and a scar on the right wrist, which the patient said was the result of a lesion like those on the scrotum, that had become a boil. The right index finger was twice its normal circumference, red and above the second joint infiltrated. The last joint was tender and practically fixed. 
Diagnosis.-Granuloma annulare, despite the unusual location, with possible tuberculosis of the finger, or hypertrophic annular lichen planus was considered. A microscopic study excluded lichen planus, and supported the concept of granuloma annulare, or sarcoid of Darier-Roussy.

Comment. - The general physical examination was negative. No thoracic signs of tuberculosis were found. The abdominal viscera seemed normal. The lymph glands were impalpable, the oculomotor system was functioning properly, and the deep tendon reflexes were slightly exaggerated. A roentgenogram of the diseased finger showed that the bones and the periosteum were unaffected.

Treatment and Course.-It was decided to base treatment on the presumptive diagnosis of granuloma annulare. Roentgen irradiation was begun with a Holzknecht unit, August 20 and until September 18 this was continued at weekly intervals, five exposures having been made. At the same time, arsenous oxid pills, beginning with $1 / 50$ grain three times daily, in increasing doses, were prescribed. Various local antipruritics were used. By September 27, no impression had been made on the lesions, and the suspicion of syphilis was reawakened. Infection was again denied, and the serum test proved faintly positive $(+)$ with cholesterinated antigen, and negative with alcoholic antigen. Nevertheless, the therapeutic diagnostic test was decided on, and a grain of mercury salicylate was injected October 1 . Three days later the patient stated that several hours after the injection the finger had become redder and more painful and that itching in the scrotum had stopped the same night. October 4, arsphenamin (0.4) was administered. By October 8 , or after one mercury and one arsphenamin injection, the swelling in the finger was reduced by half, and the pain had vanished. October 11, the scrotal lesions were one third their original size, and by October 15, they were gone. Routine combined arsenical and mercurial treatment in series was instituted, but after a rest period beginning December 13, and ending January 10, 1921, the Wassermamn reaction was +++ . Since then the patient has had two series of mercuric oxycyanid injections of $1 / 12$ grain, intravenously, twenty-seven treatments in all. Between the two series, the Wassermann reaction was found to be +++ .

\section{COMMENT}

The outstanding features of this report are the negative history, the negative serum test, the atypical character of the lesions, and above all their itching. Every fact negated the likelihood of syphilis, including the minute anatomy of the lesions, and only the therapeutic diagnostic procedure, with provocation of the Wassermann test, finally solved the problem. Without precisely seeing how the error in diagnosis could have been avoided, considering the misleading data, I cannot entirely relinquish the thought that it was the belief that itching almost precluded syphilis that most surely dulled clinical astuteness.

Phineas Abraham mentions, as already noted, that scrotal lesions may itch. The case herein reported supports the British writer's statement. Furthermore, it was a pure syphilid, one uncomplicated by any other itching dermatosis. Early syphilis is often seen in con- 
junction with scabies, and undoubtedly coexists with many other itching eruptions. In such an event, it is rarely difficult to make a correct clinical distinction between the two elements in the picture. But it is important to realize that certain syphilids themselves itch, and so not to be thrown off the track as I was when confronted with the phenomenon. Neither the appearance, nor the roentgenogram of the finger suggested syphilis. The infiltration must have been hypodermal.

\section{OTHER CASES}

At the Mount Sinai Hospital, Dr. Goldenberg and I were requested to see a woman with fingers exactly like this man's. Radiographs showed normal phalanges, but her Wassermann test was positive. The lesions disappeared under specific treatment. Instances of this sort show the futility of judging syphilis by classic standards.

Unfortunately, the most instructive cases often elude us, or I should be able to give a complete report of another baffling pruriginous syphilid. The patient was a middle-aged Austrian in the skin ward of the old German Hospital in New York. He had a generalized, intensely itching dermatosis of many years' duration, which resembled exfoliative dermatitis on a seborrheal basis. A biopsy was made, for it was thought that microscopic study might reveal the true nature of the condition. An astonishing degree of inflammation and thickening were found in the arterioles, and a lymphocytic perivascular infiltration with a few plasma cells. This so much more suggested syphilis than any of the erythrodermas, or the ordinary chronic scaling or vesicular diseases, that the patient was questioned as to syphilis, and admitted a presumptive infection in his youth. His Wassermann test was doubtful $(+-)$, but he was given an injection of mercury salicylate, and that night his itching stopped for the first time in years. Within a week, having received a second injection, his eruption had nearly completely disappeared, although all loral treatment over a number of years had failed to relieve him. He then promised to visit me for further study, but failed to.

This patient's eruption resembled syphilis even less than does granuloma annulare. It itched as intensely as did the eruption in the first case, but, as in the first case, the Wassermann test was doubtful. Whether it would have been provoked by further treatment cannot be stated. If Bruusgaard's case of cutaneous tuberculosis; resmbled pityriasis rubra (Hebra), it is not astonishing that, however rarely, syphilis may also resemble exfoliative dermatitis, and undoubtedly the same holds true of syphilitic mimicry of the ringed eruption. The amazing feature in both of the patients was intense pruritus which yielded promptly to trivial antispecific treatment. The 
itching stopped in each instance a few hours after the first injection of mercury, the involution of the lesions themselves rapidly following the usual course.

780 Madison Avenue.

\section{ABSTRACT OF DISCUSSION}

Dr. William Allen Pusey, Chicago: I recall in my experience a practically duplicate case of Dr. Highman's scrotal case of itching syphilis. The patient was a middle aged man who came to me with the diagnosis of eczema. He had an infiltrated surface, with annular lesions, the whole condition having existed for a long time. It cleared up almost miraculously under specific treatment. I think it is hardly to be called an itching syphiloderm. While it is the syphiloderm that itches, the itching is probably due to the friction and the warmth which produced irritation. It does not seem to me to come in the same category as the itching, small, folliculopapular syphilid.

Dr. Henry H. Whitenouse, New York: A case strikingly like Dr. Highman's was under my observation some twenty-three years ago, but I have never seen a second, so concluded that such cases are rare.

My case differed from Dr. Highman's in being a frank, straightforward secondary syphilid, generalized sparsely on the body and markedly on the arms. It had the brownish ham color, the distribution and grouping, so that clinically there was no mistaking its character. It was before the days of the Wassermann test and the striking symptom the woman complained of was intense itching which was so pronounced that she was fairly maniacal. She had no accompanying itching dermatitis. Under antisyphilitic treatment the itching ceased rather promptly as the eruption subsided and disappeared. Of course the itching of the early roseola is a common observation.

Dr. August Ravogl, Cincinnati: In the past we were taught that itching was never present in syphilitic eruptions, that this was one of the signs of differential diagnosis, with the exception of the mucous patches or condyloma planum which was accompanied by a distressing itching sensation. We often see the condyloma in the breast and crurogenital region, always accompanied by the itching, on account of the abrasions and the irritation caused by perspiration and seropurulent secretion.

I agree with Dr. Pusey that sometimes in the beginning of the small papular syphilid there is an itching sensation that the patients complain of, and it would suggest an association with lichen, if it were not for the other symptoms.

Dr. James Herbert Mitchell, Chicago: In a series of papers in the last two years Leredde has called attention to the occurrence of itching in syphilids and also the rôle played by syphilis in eruptions, in even neurodermatitis. $\mathrm{He}$ is convinced that in some cases they are of syphilitic origin. He began by a theoretic discussion, and in the last paper gave case histories that show that ordinary itching dermatoses are of syphilitic origin.

Dr. Walter J. Highman, New York: I think Dr. Pusey's criticism is well founded and his remarks are based on a group of cases that Phineas Abraham refers to as complicated by other dermatoses, but I believe in my case the criticism does not hold true, for the following reasons: In the first place, all the antipruritics used had no effect on the pruritus. That, I think, eliminates the hypothesis that any secondary dermatosis caused the itching. 
In the second place, the fact that the itching disappeared within a few hours after beginning antisyphilitic treatment supports the belief in its specific origin. For this reason, together with the fact that there was no itching eruption associated with the lesions, I concluded that this was a unique case, in that it was a pure syphilid with itching. There was nothing in the histologic section to show what caused the itching, but neither is there in many other disorders. 